\title{
Identificación de la secuencia del gen de la subunidad catalítica de la telomerasa en Plasmodium falciparum
}

\author{
Claudia Consuelo Rubiano ${ }^{1,2}$, Moisés Wasserman ${ }^{1,2}$ \\ ${ }^{1}$ Laboratorio de Investigación Básica en Bioquímica (LIBBIQ), Departamento de Química, Facultad de \\ Ciencias, Universidad Nacional de Colombia, Bogotá, D.C., Colombia. \\ 2 Laboratorio de Bioquímica, Instituto Nacional de Salud, Bogotá, D.C., Colombia.
}

Introducción. La enzima telomerasa participa en la regulación de la longitud de los telómeros al sintetizar nuevas repeticiones teloméricas que compensan las pérdidas en cada ronda de replicación del ADN. Por esta razón, el bloqueo de su actividad se plantea como un posible blanco de acción para detener el crecimiento de células con altas tasas de crecimiento. Tal es el caso de Plasmodium falciparum, parásito causante de la forma más grave de paludismo humano, en el cual se sabe que hay actividad de telomerasa pero no se tiene información sobre la enzima misma.

Metodología. Para hacer un acercamiento al estudio de la telomerasa en $P$. falciparum, se realizó un alineamiento múltiple de las secuencias de la subunidad catalítica de la telomerasa disponibles en bases de datos y se obtuvo una secuencia consenso, la cual se comparó con las secuencias generadas en el proyecto de genoma de $P$. falciparum. Se encontró una secuencia que podría corresponder a parte del gen de la telomerasa de $P$. falciparum. Para comprobarlo, se diseñaron iniciadores que se utilizaron en ensayos de amplificación sobre el ADN y el ARN del parásito.

Resultados. Se amplificaron fragmentos de ADN correspondientes a motivos conservados en las telomerasas y se detectó la presencia del ARNm mediante trascripción reversa y PCR sobre el ADNc generado. De esta manera, al combinar la utilización de herramientas de bioinformática y su posterior comprobación mediante técnicas de biología molecular, se obtuvo la secuencia del gen de la subunidad catalítica de la telomerasa en $P$. falciparum y se comprobó su presencia y trascripción en el parásito.

Palabras clave: telomerasa, telómero, Plasmodium falciparum, biología computacional, paludismo.

Identification of the gene sequence of telomerase catalytic subunit in Plasmodium falciparum

Introduction. The enzyme telomerase regulates telomere length by synthesis of telomeric repeats to compensate for telomeric loss in each DNA replication cycle. Therefore, telomerase is a potential target to block growth of cells with high replication rates. In Plasmodium falciparum, telomerase activity has been documented, but little information on its structure and role.

Methods. Herein, alignment of multiple sequences was undertaken comparing telomerase catalytic subunit sequences as found in existing databases. A consensus sequence was compared with the sequences in the $P$. falciparum genome project and as a result, a candidate sequence for a portion of the telomerase gene was recovered. Primer sets were designed for DNA and RNA amplifications.

Results. DNA fragments corresponding to telomerase conserved domains were amplified by using reverse transcription and PCR of cDNA. With a combination of bioinformatics and sequencing methods, the sequence of telomerase catalytic subunit gene (TERT) in $P$. falciparum was discovered, and its presence and transcription demonstrated.

Keywords:Telomerase, telomere, Plasmodium falciparum, bioinformatics, malaria 
Los telómeros son estructuras localizadas en los extremos de los cromosomas eucariotes; éstos están formados por repeticiones de ADN ricas en $\mathrm{G}$ en tándem y por proteínas asociadas. Los telómeros ejercen un efecto de capping que protege el extremo cromosómico de ser reconocido como ADN dañado por parte de la maquinaria celular $y$, de esta forma, se previenen eventos como las fusiones de cromosomas, las recombinaciones $y$, en general, las respuestas celulares ante daño en el ADN (1-3).

Los extremos de las moléculas lineales de ADN eucariote no pueden ser replicadas en su totalidad por las ADN polimerasas las cuales requieren de un iniciador de ARN para comenzar la síntesis. Esto hace que quede una región no replicada que se pierde luego de cada ronda de replicación lo que produce un acortamiento del cromosoma; este fenómeno se conoce como el "problema de la replicación final". Para solucionarlo, la mayoría de las células eucariotes usan la enzima telomerasa, la cual sintetiza nuevas repeticiones telómericas $y$, de esta forma, compensa las pérdidas de cada replicación $(4,5)$. La telomerasa es una ribonucleoproteína con acción de transcriptasa reversa que lleva consigo su propia unidad de ARN $(4,5)$. Posee un núcleo catalítico que está integrado por la subunidad catalítica (TERT, del inglés, TElomerase Reverse Transcriptase) y el componente ARN (TER, del inglés, Telomerase $R N A$ ) los cuales son indispensables para la actividad. Otras proteínas hacen parte del complejo pero no participan directamente en la catálisis; parecen ser específicas para cada especie y estar relacionadas con aspectos como la biogénesis, el ensamblaje y la regulación del complejo (6).

El mantenimiento del equilibrio telómerico implica la existencia de mecanismos que regulen el acortamiento y la elongación. Este aspecto es

\footnotetext{
Correspondencia:

Moisés Wasserman, Universidad Nacional de Colombia, Laboratorio de Investigación Básica en Bioquímica (LIBBIQ), Unidad Camilo Torres, bloque 10, nivel 4, Bogotá, D.C., Colombia.

Teléfono: (571) 316 5000, extensión 18367

mwassermannl@unal.edu.co
}

Recibido: 02/08/04; aceptado: 25/01/05 fundamental para la estabilidad genética y, por tanto, para la supervivencia celular $(7,8)$. EI desequilibrio hacia el acortamiento se ha asociado con procesos celulares como la senescencia, mientras que el caso contrario se asocia con la inmortalización celular, particularmente en fenómenos como el cáncer.

Por lo anterior, la actividad de telomerasa o la presencia de otro mecanismo que compense la pérdida del ADN telomérico resulta crítico sobre todo para células que presentan altas tasas de replicación. Desde esta perspectiva, el bloqueo de la actividad telomerasa podría constituir un blanco de acción para detener el crecimiento de este tipo de células. Éste es el caso de Plasmodium falciparum, el parásito que produce la forma de paludismo humano más grave y que presenta una tasa de crecimiento muy alta, limitada sólo por las condiciones del cultivo (in vitro) o la respuesta inmune del huésped (in vivo).

Aunque en este organismo se ha reportado actividad de telomerasa (9-11), no existe a la fecha información alguna sobre los componentes de la enzima. Sumado a esto, llama la atención el hecho de que $P$. falciparum presenta repeticiones teloméricas variables en la secuencia GGGTTT/ CA mayor del $80 \%$, a diferencia de la mayoría de los organismos estudiados donde la telomerasa sintetiza repeticiones invariables (12). Con base en estas consideraciones, en este trabajo se buscó hacer un primer acercamiento al estudio de la subunidad catalítica de la telomerasa (TERT) en P. falciparum.

La subunidad catalítica (TERT) se identificó inicialmente en el ciliado Euplotes aediculatus como p123 (13) y, luego, se encontró que era homóloga con Est2p, una proteína de levaduras (Saccharomyces cerevisiae) requerida para el mantenimiento de los telómeros $(14,15)$. Ambas proteínas tienen motivos de transcriptasa reversa (RT-like motifs) que al ser alterados producen pérdida de la actividad de telomerasa y reducción en la longitud telomérica. Posteriormente, se identificaron homólogos de TERT en Schizosaccharomyces pombe, humano, ratón, $T$. termophila, Oxitrichia trifallax y Arabidopsis spp. $(16-25)$. Recientemente se publicaron las 
secuencias de posibles subunidades TERT de Giardia lamblia y Caenorhabditis elegans (26) así como de Xenopus (27).

Las TERT contienen 7 motivos (RT1, RT2, A, B, $C, D$ y $E$ ) que son comunes a todas las transcriptasas reversas, cuya presencia es consistente con el papel de la telomerasa en la polimerización de ADN sobre una plantilla de ARN (28). Además de los motivos RT, las TERT poseen un motivo específico para la telomerasa (motivo $\mathrm{T}$ ), localizado hacia el $\mathrm{N}$-terminal de los motivos RT. Las mutaciones de aminoácidos conservados en este motivo producen una reducción en la actividad de la telomerasa in vitro $(19,29)$. Los protozoarios ciliados tienen, además, otro motivo conservado dentro de TERT (motivo CP) de función desconocida, el cual es menos conservado en otras especies (20).

También, se han descrito otros motivos funcionalmente importantes localizados tanto hacia la región $\mathrm{N}$-terminal como hacia la C-terminal (30).

\section{Materiales y métodos}

\section{Cultivo de parásitos}

Se cultivaron parásitos de la cepa colombiana FCB-2 siguiendo el método de Trager y Jensen (31) y usando sangre humana tipo O Rh+. La sangre fue suspendida al $5 \%$ en medio de cultivo RPMI-1640 con suplemento de hipoxantina 0,2 mM, HEPES $25 \mathrm{mM}, \mathrm{NaHCO}_{3} 32 \mathrm{mM}$, glutatión reducido (GSH) $1 \mathrm{mg} / \mathrm{L}$, gentamicina $50 \mu \mathrm{g} / \mathrm{mL}$ y suero humano inactivado al $10 \%$. La extracción de los ácidos nucleicos se llevó a cabo a partir de cultivos asincrónicos aunque la mayoría de los parásitos (>80\%) se encontraba en estadios maduros (trofozoítos, correspondientes a 30-40 horas del ciclo intraeritrocítico).

\section{Extracción de ADN}

Para la obtención del ADN se partió de cultivos de $P$. falciparum mantenidos con sangre libre de células blancas por tratamiento con FicollHypaque. Cuando el cultivo alcanzó una parasitemia de $10 \%$, aproximadamente, se centrifugó a $800 \mathrm{~g}$ durante 5 minutos; el sedimento se resuspendió en 10 volúmenes de una solución de saponina $0,15 \%$ en solución tampón isotónico HBS y se incubó 10 minutos a temperatura ambiente. Los parásitos se recuperaron por centrifugación a $15.000 \mathrm{~g}, 10$ minutos, $4^{\circ} \mathrm{C}$; el botón se lavó dos veces con HBS, se resuspendió en 3 volúmenes de solución tampón de lisis (proteinasa

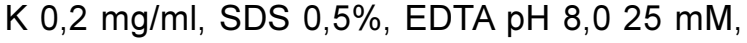
Tris- $\mathrm{HCl} \mathrm{pH} 8,010 \mathrm{mM}$ y NaCl 0,1 mM) y se incubó durante 18 horas a $50^{\circ} \mathrm{C}$. El lisado fue sometido a extracciones fenólicas muy suaves seguidas por una extracción con fenol-cloroformo (1:1) y, finalmente, se dializó contra 4 litros de tampón TE (Tris-HCl 10 mM pH 7,6; EDTA 1 mM) en 24 horas. La concentración del ADN extraído se determinó por espectrofotometría a $260 \mathrm{~nm}$.

\section{Extracción de ARN}

Los parásitos fueron liberados de los eritrocitos mediante lisis con saponina en la misma forma que se describió para la extracción de ADN. Se extrajo ARN total mediante lisis de los parásitos con una solución de isotiocianato de guanidina 4 $\mathrm{M}, \beta$-mercaptoetanol $0,1 \mathrm{M}$, citrato de sodio $\mathrm{pH}$ $7,025 \mathrm{mM}$, y sarkosilato de sodio $0,5 \%$, seguida de una extracción fenol-cloroformo y ultracentrifugación por 20 horas a $120.000 \mathrm{~g}$ a $20^{\circ} \mathrm{C}$ en colchones de cloruro de cesio 5,7 M. EI ARN se resuspendió en solución de Tris- $\mathrm{HCl}, \mathrm{pH} 7,4,10$ $\mathrm{mM}$, EDTA $5 \mathrm{mM}$, SDS $0,1 \%$ y se precipitó con 2,5 volúmenes de etanol en presencia de acetato de sodio $0,3 \mathrm{M}$. EI ARN recuperado por centrifugación se lavó con isopropanol al $70 \%$, se secó al vacío y se resuspendió en agua tratada con dietilpirocarbonato. La concentración delARN extraído se determinó por espectrofotometría a 260 $\mathrm{nm}$.

\section{Análisis por bioinformática}

Los alineamientos múltiples se llevaron a cabo utilizando el programa Clustal X (32). Para los alineamientos iniciales se consideraron las secuencias de TERT de diversos organismos, reportadas hasta el primer semestre del 2000. Para el alineamiento final se incluyeron otras secuencias que fueron reportadas posteriormente junto con la posible secuencia de TERT identificada aquí para $P$. falciparum.

La búsqueda de homologías se realizó mediante el algoritmo de búsqueda BLAST (Basic Local 
Aligment Search Tool) en sus distintas variaciones BLASTn, la cual se utilizó para la comparación de secuencias de ADN; esto se refiere a los productos obtenidos por PCR y RT-PCR comparados con la secuencia del contig de $P$. falciparum; BLASTp, usada para la comparación de las secuencias proteicas de TERT reportadas en las bases de datos para los distintos organismos y tBLASTn, la cual permitió comparar la secuencia proteica del consenso generado para las proteínas TERT con las secuencias de ADN de la base de datos del genoma de $P$. falciparum (33), traducidas en los 6 marcos de lectura posibles. Se utilizaron los parámetros estándar para el programa, disponibles en el servidor NCBI BLAST; bajo estos parámetros, la matriz que se utiliza por defecto es BLOSUM 62.

Para encontrar la secuencia completa del gen de TERT, habiendo encontrado una parte de ésta, se usó el programa buscador de genes GLIMMERM, de cuyo uso se comentará en la sección de discusión de resultados.

\section{Diseño de iniciadores}

Se diseñaron 5 iniciadores para lograr la amplificación de las regiones correspondientes al ADN y al ADNc de los dominios T y BCD de la proteína TERT; los iniciadores diseñados corresponden a una pareja (sentido y antisentido) para el dominio $T$ y dos parejas (dos iniciadores antisentido con un único iniciador sentido), para el dominio BCD. Para el diseño se utilizó el programa PRIMER (Primer designer, versión 1.01) sobre las regiones de la secuencia EMBL AL049181:CROMO 13 de $P$. falciparum que mostraron similitud con la secuencia consenso de TERT (la secuencia y la localización esquemática de estos iniciadores se muestran en el cuadro 1 y figura 1, respectivamente). Como criterios de inclusión se tuvieron en cuenta el uso de residuos conservados, la no formación de estructuras secundarias, el contenido de $\mathrm{G}+\mathrm{C}$ similar al de la plantilla (20-30\%), la longitud (entre 20 y 30 bases) y la temperatura de anillaje o fusión (cercana entre ellos).

\section{Amplificaciones}

Se llevaron a cabo amplificaciones mediante PCR utilizando $100 \mathrm{ng}$ de ADN genómico de $P$. falciparum, $\mathrm{MgCl}_{2} 1,5 \mathrm{mM}$, iniciadores $1 \mu \mathrm{M}$, dNTP $200 \mu \mathrm{M}$ de cada uno y $2,5 \mathrm{U}$ de Taq ADN polimerasa (Promega). En algunos casos fue necesario variar la concentración de $\mathrm{MgCl}_{2}$ entre 1,5 y $4 \mathrm{mM}$ y de iniciadores entre 1 y $4 \mu \mathrm{M}$. El perfil de amplificación consistió en un ciclo de $94^{\circ} \mathrm{C}, 2$ minutos, 40 ciclos de $94^{\circ} \mathrm{C}, 30$ segundos, anillaje (entre 37 y $45^{\circ} \mathrm{C}$ ), 1 minuto y $72^{\circ} \mathrm{C}, 2$ minutos y, finalmente, 1 ciclo de $72^{\circ} \mathrm{C}, 5$ minutos.

Se realizaron reacciones de transcripción reversa y amplificación (RT-PCR), utilizando el estuche comercial Access RT-PCR System (Promega) que permite realizar la transcripción reversa y la amplificación del ADNc en un mismo tubo. Cada reacción se llevó a cabo en un volumen final de $25 \mu \mathrm{L}$ usando $200 \mu \mathrm{M}$ de cada dNTP, $1 \mu \mathrm{M}$ de $\mathrm{MgSO}_{4}, 1 \mu \mathrm{M}$ de cada iniciador, $0,1 \mathrm{U} / \mu \mathrm{l}$ de Taq ADN polimerasa, $0,1 \mathrm{U} / \mu \mathrm{l}$ de trancriptasa reversa y $100 \mathrm{ng}$ de ARN total. La transcripción reversa se llevó a cabo a $45^{\circ} \mathrm{C}, 60$ minutos, y para la posterior amplificación se siguió el mismo perfil de temperaturas antes descrito para el PCR.

Los productos obtenidos tanto por PCR como por RT-PCR se sometieron a electroforesis horizontal en gel de agarosa, tinción con bromuro de etidio y

Cuadro 1. Características de los iniciadores diseñados para amplificar regiones del gen o el cADN de TERT.

\begin{tabular}{llccc}
\hline $\begin{array}{l}\text { Nombre } \\
\text { iniciador }\end{array}$ & \multicolumn{1}{c}{ Secuencia $\left(\mathbf{5}^{\prime} \rightarrow \mathbf{3}^{\prime}\right)$} & $\begin{array}{c}\text { Tamaño } \\
\text { (bases) }\end{array}$ & \% de G+C & $\begin{array}{c}\text { Temperatura del } \\
\text { del } \\
\text { anillaje } \\
\left({ }^{\circ} \mathbf{C}\right)\end{array}$ \\
\hline T s & AATGTATACCTATCAAATTATTAG & 24 & 21 & 58 \\
Ts & CCAAATTTTTCTATCAAAGA & 20 & 25 & 50 \\
BCD s & TTATCTAATATATTGTGCTCC & 21 & 29 & 54 \\
BCD As1 & ATCAATAAATCGGAGTATGAG & 21 & 29 & 56 \\
BCD As2 & TCTAGATATGCATAATATAGG & 21 & 29 & 52 \\
BCD As3 & GATGAATTAATATTACTTCCC & 21 & 29 & 54 \\
\hline
\end{tabular}




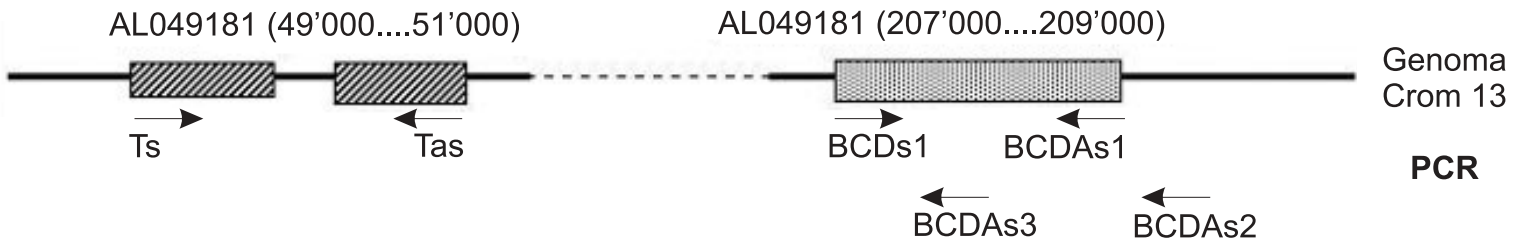

Figura 1. Representación esquemática de las regiones de secuencia de TERT correspondientes a los posibles motivos T y BCD en la secuencia de $P$. falciparum. Se muestran también las posiciones de los iniciadores diseñados.

visualización por trasiluminación con luz UV $(254$ $\mathrm{nm})$. Las imágenes obtenidas se analizaron usando el programa ONE-Dscan (Scan analytics). Los productos amplificados se purificaron a partir de las reacciones de PCR o RT-PCR usando el estuche comercial CONCERT TM PCR Extraction system (Gibco-BRL) o a partir de los geles de agarosa usando CONCERTTM Rapid Gel Extraction system (Gibco-BRL).

\section{Ensayos de PCR anidado e hibridación}

Estas dos metodologías se usaron para comprobar la ubicación de algunos fragmentos amplificados dentro de otros de mayor tamaño. Los ensayos de PCR anidado se llevaron a cabo en las mismas condiciones de reacción antes descritas para las amplificaciones por PCR. Se utilizó como plantilla $1 \mu \mathrm{l}$ del producto amplificado en lugar de ADN genómico. Como controles se incluyeron reacciones usando ADN genómico como plantilla y reacciones $\sin$ ADN.

Para los ensayos de hibridación se empleó la técnica de dot-blot. Se colocaron $5 \mu \mathrm{l}$ del fragmento de ADN de mayor tamaño sobre una membrana de nylon (Hybond $\mathrm{N}$ ) en forma de dot y se hibridó con el fragmento interno de ADN marcado con $[\alpha 32 P] A T P$ mediante PCR. La hibridación se llevó a cabo $\mathrm{O} / \mathrm{N}$ a $42^{\circ} \mathrm{C}$, en una solución de formamida al $50 \%$, sulfato de dextrán al $5 \%$, SSC $6 \mathrm{X}$, Denhardt $10 \%$ y $10 \mu \mathrm{g} / \mathrm{ml}$ de ADN de esperma de salmón. Luego de retirar la sonda se hicieron lavados con SSC $2 \mathrm{X}$, SDS $0,1 \%$ y SSC $0,1 \mathrm{X}$, SDS $0,1 \%$ y se expuso la membrana sobre película

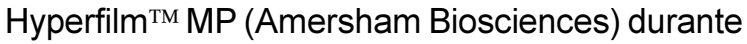
1 hora.

\section{Resultados}

Localización preliminar de la secuencia de TERT en el genoma de P. falciparum

Con el programa Clustal X (32) se realizó un alineamiento múltiple con las secuencias de TERT reportadas hasta el primer semestre de 2000. Las secuencias utilizadas para este alineamiento fueron: Euplotes aediculatos: sp|O00939|TERT_EUPAE; Oxytrichia trifallax: sp|O 76332 |TERT_OXYTR; ratón: sp|O70372|TERT_MOUSE; humano: sp|O14746| TERT_HUMAN; Tetrahymena termophila: sp|O77448|TERT_TETTH; Schizosaccharomyces pombe sp|O13339| TERT_SCHPO, y Saccharomyces cerevisiae: sp|Q06163| TERT_YEAST.

Este primer alineamiento permitió identificar el dominio $\mathrm{T}$, característico de la familia de las telomerasas y los dominios 1, 2, A, B, C y D de las transcriptasas reversas. En la figura $1 \mathrm{se}$ muestra en forma esquemática el resultado de estos alineamientos para los motivos T y BCD. Estas regiones se utilizaron para el posterior diseño de los iniciadores cuya ubicación también se muestra en el mismo esquema.

El paso siguiente al alineamiento fue construir una secuencia consenso para TERT y usarla para buscar secuencias relacionadas en la base de datos del genoma de $P$. falciparum; en este paso se usaron las secuencias consignadas hasta el primer semestre de 2000 en http:// www. plasmodb.org (33). Dos regiones del consenso generado, correspondientes al motivo $T$ y a los motivos BCD, presentaron similitud con la secuencia EMBLAL049181: CROMO 13 de $P$. falciparum (valor de e para el motivo T, $4 \mathrm{e}^{-14}$; similitud, $82 \%$; identidad, $66 \%$; valor de e para el motivo BCD, $5 \mathrm{e}^{-10}$; similitud, $77 \%$; identidad, $52 \%$ ). Este hecho hizo pensar que se trataba de las regiones codificantes en el genoma de $P$. falciparum para dichos motivos en la proteína; por eso, para amplificar estas regiones, se diseñaron los iniciadores cuya secuencia y localización se 
muestran en el cuadro 1 y figura 1 , respectivamente.

\section{Amplificación de regiones del gen de TERT correspondientes a los dominios $T$ y BCD de la proteína}

Se estandarizaron las condiciones de amplificación mostradas en el cuadro 2, junto con los tamaños de los productos amplificados. En la figura 2 se muestran los productos obtenidos en las amplificaciones por PCR. Con los iniciadores Ts y Tas se obtuvo un fragmento de $600 \mathrm{pb}$, aproximadamente (figura $2 A$ ), y con las parejas de iniciadores BCDs-BCDAs1 y BCDs-BCDAs2 se obtuvieron fragmentos de 200 y $300 \mathrm{pb}$, respectivamente (figura 2B). Estos tamaños están de acuerdo con los tamaños esperados para cada fragmento a partir de la secuencia de la cual se partió para diseñar los iniciadores. Además, de los productos de $600 \mathrm{pb}$ y $200 \mathrm{pb}$ se obtuvo parcialmente la secuencia, la cual fue alineada con la secuencia EMBL AL049181: CROMO 13 usando el programa BLASTn. La correspondencia tanto en tamaño como en secuencia entre los productos amplificados y la secuencia inicial de $P$. falciparum permite decir que estos fragmentos corresponden a regiones del gen de TERT de $P$. falciparum codificantes para los dominios $T$ y $B C D$ de la proteína.

Al amplificar con los iniciadores Ts y BCDas1 se obtuvo un producto de $1.800 \mathrm{pb}$, aproximadamente (figura 2C); este correspondería a la región del gen comprendida entre los dominios Ty BCD de TERT. Para comprobar esta afirmación se realizó una reacción de PCR anidado utilizando este fragmento como plantilla y amplificando con las parejas de iniciadores Ts-Tas y BCDs-BCDas1. Se esperaría que si el fragmento de $1.800 \mathrm{pb}$ contiene a los otros dos, los productos del PCR anidado serían del mismo tamaño a los obtenidos sobre ADN con los respectivos iniciadores.

En efecto, con los iniciadores BCDs y BCDas1 se obtuvo un producto del mismo tamaño amplificando sobre ADN y sobre el fragmento de $1.800 \mathrm{pb}$ (figura $3 \mathrm{~A}$, carriles 3 y 4 ). Con los iniciadores Ts y Tas también se obtiene un producto bien definido aunque de tamaño un poco mayor sobre el producto de $1.800 \mathrm{pb}$ con respecto al obtenido sobre ADN (figura $3 A$, carriles 1 y 2 ).

Ante este resultado y con la intención de comprobar que el fragmento de $1.800 \mathrm{pb}$ efectivamente contiene al producto de $600 \mathrm{pb}$, se hizo un ensayo de dot-blot utilizando como sonda el producto de $600 \mathrm{pb}$ obtenido sobre ADN marcado con $\left[\alpha^{32} P\right]$ dATP. Este resultado se muestra en la figura 3B; se observa que hay hibridación tanto con el punto de aplicación que contiene el producto de $600 \mathrm{pb}$ (punto 1) como con el que contiene el producto de $1.800 \mathrm{pb}$ (punto 2) pero no con el que contiene el producto de $200 \mathrm{pb}$ (punto 3 ) ni con el ADN no relacionado (punto 4). La intensidad de la señal es menor en el punto 2 que en el punto 1 ; esto puede deberse a que la amplificación con los iniciadores Ts-Tas (punto 1) es más eficiente que con Ts-BCDas 1 (punto 2), teniendo en cuenta que para hacer las siembras de los puntos (dots) se utilizaron $5 \mu \mathrm{l}$ de los productos de PCR, la cantidad de ADN en cada uno puede ser diferente. Con estos dos ensayos se comprobó que el fragmento de $1.800 \mathrm{pb}$ contiene los obtenidos previamente de 600 y $200 \mathrm{pb}$, es decir, que corresponde a la región del gen que codifica para la región comprendida entre los dominios $T$ y $B C D$ de TERT.

\section{Amplificación de regiones del ADNc de TERT}

Al realizar transcripción reversa sobre el ARN total del parásito y posterior amplificación utilizando los

Cuadro 2. Resumen de las condiciones estandarizadas de amplificación y el tamaño de los productos obtenidos en los ensayos de PCR con los iniciadores diseñados.

\begin{tabular}{lccccc}
\hline Iniciadores usados & $\begin{array}{c}\text { Tamaño del producto } \\
\text { (pb, aproximadamente) }\end{array}$ & $\begin{array}{c}\text { ADN plantilla } \\
(\mathbf{n g})\end{array}$ & $\begin{array}{c}\mathbf{M g C l}_{\mathbf{2}} \\
(\mathbf{m ~ M})\end{array}$ & $\begin{array}{c}\text { Iniciadores } \\
(\boldsymbol{\mu} \mathbf{M})\end{array}$ & $\begin{array}{c}\text { Temperatura del anillaje } \\
\left({ }^{\circ} \mathbf{C}\right)\end{array}$ \\
\hline Ts + Tas & 600 & 100 & 1,5 & 1 & 45 \\
BCDs + BCDas1 & 200 & 100 & 2,5 & 1 & 45 \\
BCDs + BCD as2 & 300 & 100 & 2,5 & 1 & 45 \\
Ts + BCDas1 & 1800 & 100 & 4,0 & 2 & 37 \\
\hline
\end{tabular}



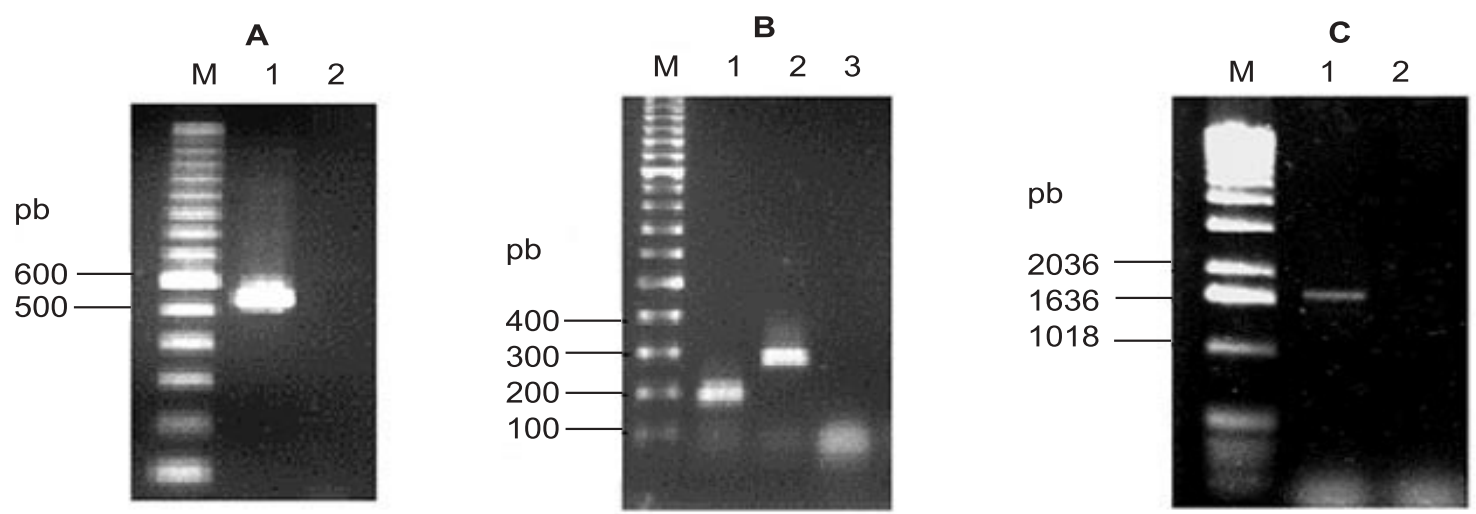

Figura 2. Fragmentos del gen de TERT amplificados mediante PCR.

Geles de agarosa teñidos con bromuro de etidio donde se muestra:

(A) Región del gen que codifica el motivo T. M: marcador de tamaño (ladder $100 \mathrm{pb}$, Promega); carril 1: producto de, aproximadamente, $600 \mathrm{pb}$, obtenido con los iniciadores Ts y Tas; 2: control negativo (sin ADN)

(B) Región del gen que codifica parte del motivo BCD. M: marcador de tamaño (ladder 100 pb, Promega); carril 1: producto de, aproximadamente, $200 \mathrm{pb}$, obtenido con los iniciadores BCDs y BCDas1, 2: producto de, aproximadamente, $300 \mathrm{pb}$, obtenido con los iniciadores BCDs y BCD as2; 3: control negativo (sin ADN).

(C) Región del gen que codifica la zona comprendida entre los motivos T y BCD. M: marcador de tamaño (ladder $1 \mathrm{~kb}, \mathrm{BRL}$ ); carril 1: producto de, aproximadamente, $1.800 \mathrm{pb}$ obtenido con los iniciadores Ts y BCD as1, 2: control negativo (sin ADN).

iniciadores diseñados sobre el ADNc generado (reacciones de RT-PCR), se obtuvieron los productos que se muestran en la figura 4 . Los fragmentos obtenidos son de los mismos tamaños que los obtenidos sobre ADN: aproximadamente, $600 \mathrm{pb}$ con los iniciadores Ts y Tas; aproximadamente, $200 \mathrm{pb}$ con los iniciadores BCDs y BCDas 1 y, aproximadamente, 1.800 con los iniciadores Ts y BCDas1. De los productos de
$600 \mathrm{pb}$ y de $200 \mathrm{pb}$ se obtuvieron parcialmente las secuencias y se comprobó la correspondencia en secuencia con los obtenidos sobre ADN.

\section{Obtención de la posible secuencia completa del gen de TERT de P. falciparum}

Con las secuencias de los productos amplificados y la culminación de la fase de secuencia del proyecto de genoma de $P$. falciparum (segundo
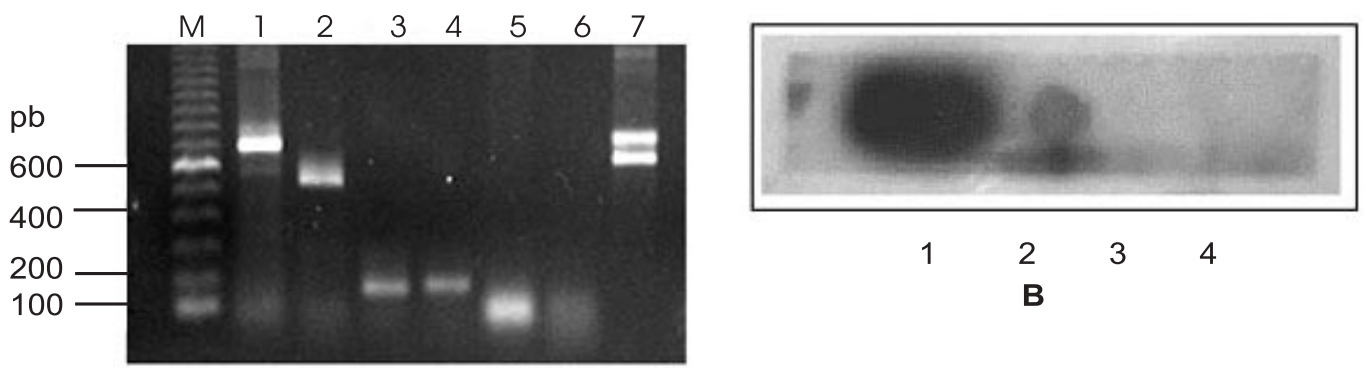

A

Figura 3. Comprobación de que el producto de 1.800 pb contiene a los de 600 y 200 pb.

(A) Electroforesis en gel de agarosa que muestra el resultado de la reacción de PCR anidado. M: marcador de tamaño (ladder 100 pb, BRL); carril 1: reacción de PCR usando como plantilla el fragmento de $1.800 \mathrm{pb}$ y amplificando con los Iniciadores Ts y Tas; carril 2: reacción como en 1 usando ADN del parásito como plantilla; carril 3: reacción usando como plantilla el fragmento de $1.800 \mathrm{pb}$ y amplificando con los Iniciadores BCDs y BCDas1; carril 4: reacción como en 3 usando ADN del parásito como plantilla; carril 5: control negativo (sin ADN) de la amplificación con los Iniciadores Ts y Tas; carril 6: control negativo (sin ADN) de la reacción con los iniciadores BCDs y BCDas1; carril 7: control positivo de las amplificaciones. (B) Ensayo de hibridación (dot-blot) usando el producto de 600 pb como sonda; caril 1: punto o dot que contiene el producto de $600 \mathrm{pb}$; carril 2: punto o dot con el producto de $1.800 \mathrm{pb}$; carril 3: punto o dot con el producto de $200 \mathrm{pb}$; carril 4: punto o dot con un ADN no relacionado (ADN de fago I). 
Cuadro 3. Secuencias de TERT utilizadas para el alineamiento múltiple final.

\begin{tabular}{lrllllll}
\hline & aa & PM & pl & & aa & PM & pl \\
\hline Eupae & 1.031 & 123 & 10,1 & Mouse & 1.122 & 128 & 10,7 \\
Oxytr & 1.132 & 134 & 10,3 & Xenopus & 1.191 & 138 & 9,55 \\
Tetth & 1.117 & 133 & 10,0 & C. parvum & 1.474 & 170 & 9,47 \\
Yeast & 884 & 103 & 10,0 & Rice & 1.259 & 144 & 9,48 \\
Achp & 988 & 116 & 10,6 & Arabidopsis & 1.123 & 130 & 9,62 \\
C. albicans & 867 & 101 & 9,48 & Paramecium & 895 & 107 & 9,76 \\
Hum & 1.132 & 127 & 11,3 & Giardia & 960 & 110 & 9,72 \\
& & & & P. falciparum & 2.518 & 304 & 9,96 \\
\hline
\end{tabular}

aa: número de aminoácidos; PM: peso molecular de la proteína (kd); pl: punto isoeléctrico de la proteína.

Eupae: Euplotes aediculatus; Oxytr: Oxytricha trifallax; Tetth: Tetrahymena thermophila; Yeast: Saccharomyces cerevisiae; Schp: Schizosaccharomyces pombe; C. albicans: Candida albicans; Huma: Homo sapiens; Mouse: Mus musculus; Xenopus: Xenopus lavéis; C. parvum: Cryptosporidium parvum; Rice: Oryza sativa; Arabidopsis: Arabidopsis thaliana; Paramecium: Paramecium tetraurelia; Giardia: Giardia lamblia

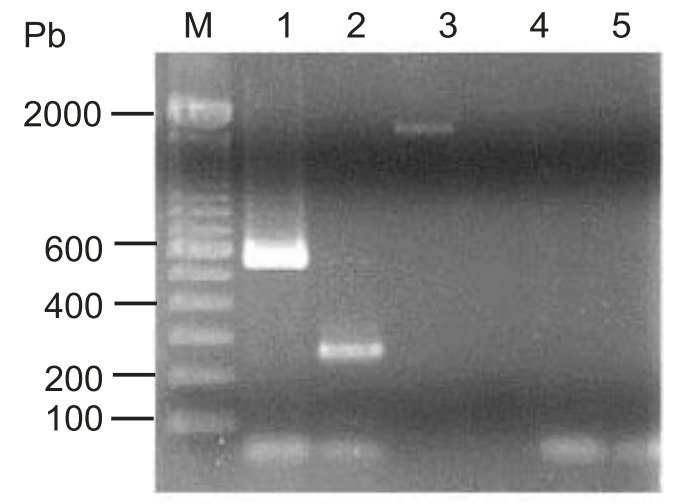

Figura 4. Fragmentos del ADNc de TERT amplificados mediante RT-PCR.

Gel de agarosa teñido con bromuro de etidio con los resultados de las reacciones de RT-PCR: M: marcador de tamaño (ladder 100 pb. Promega); carril 1: reacción con los iniciadores Ts y Tas; carril 2: reacción con los iniciadores BCD s y BCDas2; carril 3: producto de los iniciadores Ts y BCDas 1; carril 4: control negativo (sin transcriptasa reversa); carril 5: control negativo (sin ARN plantilla).

semestre de 2001) fue posible hacer un acercamiento a la secuencia completa del gen de TERT en el parásito. Por medio del programa BLASTn se compararon las secuencias obtenidas de los productos de PCR con todas las secuencias disponibles del cromosoma 13 de $P$. falciparum (33); allí se ubicó un nuevo contig:chr13_4000065 que contenía al EMBLAL049181:CROMO 13 que se había encontrado inicialmente y que se usó para el diseño de los iniciadores. Sobre la secuencia del contig chr13_400065 (28510 nucleótidos), se usó el programa GLIMMERM (34) para identificar las posibles regiones codificantes.

Se encontró un posible gen en la región comprendida entre las posiciones 4276 y 11832 , la cual incluye la región donde se habían encontrado las secuencias obtenidas de los fragmentos amplificados. Igualmente, esta región contiene la secuencia AL049181:CROMO13 identificada inicialmente y que se usó como base para el diseño de los iniciadores.

El posible gen tiene una longitud de 7.556 nucleótidos, lo cual traduce una secuencia proteica de 2.518 aminoácidos; esta proteína hipotética tendría un peso molecular de $304 \mathrm{kd}$ y un punto isoeléctrico (pl) de 9.96 , datos calculados usando herramientas disponibles en http:// www.expasy.org (35). Si ésta correspondiera a la secuencia de TERT de $P$. falciparum, el tamaño sería mayor al de las otras TERT reportadas mientras que el pl sería similar al de dichas proteínas; estos datos iniciales obtenidos con herramientas de bioinfomática pueden comprobarse posteriormente mediante experimentación.

Luego de obtener la posible secuencia de la TERT de $P$. falciparum, se volvió a hacer uso del programa Clustal-X con el fin de realizar nuevamente un alineamiento múltiple que incluyera esta secuencia, además de las consideradas inicialmente, y las recientemente reportadas. Se buscaba identificar en todas las secuencias, pero particularmente en la de $P$. falciparum, los motivos ya descritos para TERT. Las proteínas TERT 


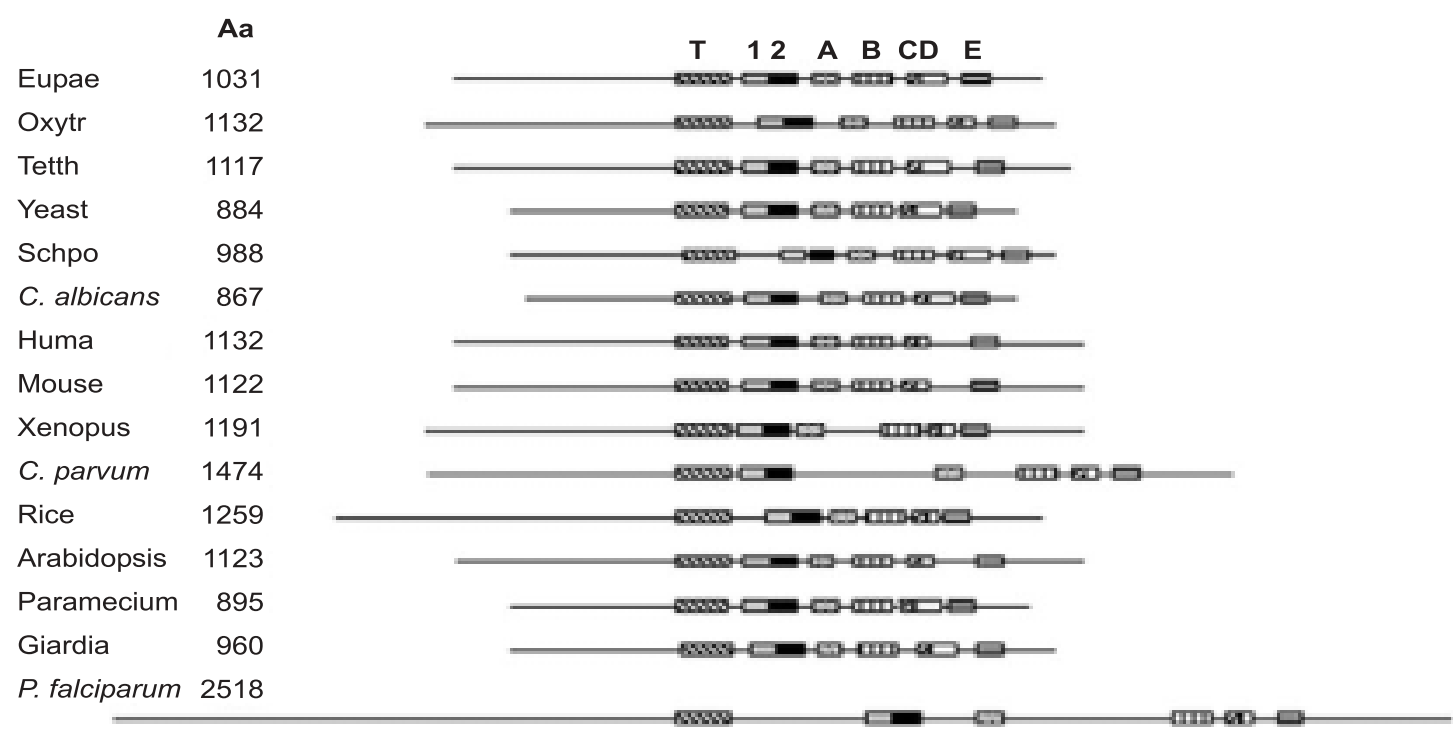

Figura 5. Esquema del alineamiento múltiple final de las secuencias de TERT.

Se indican las secuencias que se emplearon para el alineamiento así como la longitud de cada una de ellas (en aminoácidos). En la parte superior del esquema se muestra la convención utilizada para cada motivo identificado.

consideradas para este nuevo alineamiento se describen en el cuadro 3.

En este alineamiento se identificaron los motivos 1 (aa 1410 a 1432), 2 (aa 1433 a 1445), A (aa 1560 a 1595), B (aa 1922 a 1954), C (aa 1975 a 1994), D (aa 1995 a 2021) y E (aa 2090 a 2104). Al considerar la longitud de las secuencias utilizadas para el alineamiento y la localización en estas secuencias de los dominios conservados de transcriptasa reversa $(1,2, A, B, C, D$ y E) y el dominio $T$, se realizó el esquema mostrado en la figura 5 el cual resume los hallazgos del alineamiento. Allí se muestra en forma esquemática la identificación de todos los dominios conservados descritos para las TERT en las secuencias alineadas, incluida la de $P$. falciparum.

\section{Discusión}

El objetivo de realizar alineamientos múltiples entre secuencias pertenecientes a una misma familia o relacionadas entre sí, es identificar regiones en las cuales dichas secuencias exhiben conservación o divergencia $(32,36)$. Esta información puede ser útil desde el punto de vista funcional ya que se pueden identificar regiones 0 dominios compartidos relacionados con funciones ya caracterizadas en otras familias. Además, el encontrar regiones conservadas aún sin caracterizar permite encaminar experimentos para indagar su función.

El programa utilizado en este caso (Clustal $X$ ) es clasificado como un método de alineamiento progresivo que utiliza el hecho de que secuencias similares muy probablemente son evolutivamente relacionadas. Así, este método compara secuencias en pares siguiendo el orden de un árbol familiar: las secuencias similares son alineadas primero $y$, posteriormente, se añaden las más distantes. Una vez se han calculado los valores para cada secuencia con relación a las otras, se usan para agrupar las secuencias y, luego, se alinean los grupos entre sí para generar el alineamiento final (32). Como parte de esta operación, el programa puede producir la información requerida para generar un árbol filogenético. De esta forma, el alineamiento realizado con las TERT permitió identificar el dominio $T$, característico de la familia de las telomerasas y los dominios $1,2, A, B, C$ y D de las transcriptasas reversas.

El paso siguiente al alineamiento fue construir una secuencia consenso para TERT y usarla para buscar secuencias relacionadas en la base de 
datos del genoma de $P$. falciparum. La búsqueda a partir de secuencias de proteínas permite detectar homologías más lejanas en comparación con las realizadas a partir de $\operatorname{ADN}(32,37)$. Los aminoácidos tienen características químicas que permiten asignar grados de similitud más que el simple reconocimiento de identidad o no; además, al comparar las secuencias de ADN se presenta un porcentaje de ruido debido a las mutaciones en la tercera base de cada codón y a los marcos de lectura no codificantes. Esto hace que las búsquedas de proteínas sean muy valiosas para detectar relaciones evolutivas (secuencias homólogas) mientras que las búsquedas de ADN lo sean para localizar regiones de secuencia cercanamente idénticas.

Los valores estadísticos (valores e) obtenidos de la comparación de la secuencia consenso para las proteínas TERT con las secuencias de ADN traducidas contenidas en la base de datos del proyecto de genoma de $P$. falciparum, fueron del orden de $1 \mathrm{e}^{-10}$ a $1 \mathrm{e}^{-12}$. Esto deja ver que la búsqueda realizada por este método es confiable y tiene alta probabilidad de ser biológicamente significativa. Cuando se utilizan métodos bioinformáticos para el análisis de secuencias, los resultados se deben tomar con precaución ya que siempre se trata de datos probables; sin embargo, cuanto más pequeños sean los valores e, como en este caso, mayor será la confiabilidad del resultado.

Los resultados anteriores, obtenidos mediante el uso de herramientas de bioinfomática, se corroboraron experimentalmente; es así como mediante experimentos de PCR se amplificaron regiones que en tamaño y secuencia corresponden a lo predicho en el análisis bioinfomático (figura 2). Además, los ensayos de PCR anidado e hibridación llevados a cabo (figura 3) permitieron comprobar que, de acuerdo con lo esperado, los fragmentos amplificados que corresponden a los motivos T y BCD de la proteína están contenidos en el fragmento de $1.800 \mathrm{pb}$ obtenido al amplificar con los iniciadores externos Ts y BCDas.

Los resultados obtenidos en los experimentos de RT-PCR (figura 4) permiten establecer dos hechos importantes: 1) el gen de TERT es transcripcionalmente activo como se comprobó por el hecho de haber obtenido productos de amplificación sobre el cADN proveniente de ARN del parásito; y 2) no existen intrones entre las regiones que codifican para los dominios $T$ y $B C D$ ya que el tamaño del fragmento amplificado con los iniciadores Ts y BCDas sobre ADN $(1.800 \mathrm{pb}$, figura 2) es el mismo al obtenido con dichos iniciadores a partir del ARN (1.800 pb, figura 4).

Las secuencias obtenidas de algunos de los fragmentos amplificados permitieron establecer una correspondencia en secuencia, adicional a la de tamaño, entre los productos amplificados y la secuencia original de $P$. falciparum. Estas secuencias, junto con el avance del proyecto de genoma de $P$. falciparum, permitieron hacer un acercamiento mediante bioinfomática a la secuencia completa del gen de TERT. Para ello, se recurrió al programa GLIMMERM, el cual es un programa "buscador de genes" desarrollado específicamente para eucariotes pequeños cuya densidad génica está alrededor del 20\% (38). Está basado en el programa GLIMMER el cual ha probado ser muy eficiente para encontrar genes bacterianos $(38,39)$. La base de GLIMMERM es un algoritmo dinámico de programación que considera todas las combinaciones de posibles exones para la inclusión en un modelo de gen y escoge la mejor de estas combinaciones (38). Este programa se ha probado con $P$. falciparum, $A$. thaliana, Oryza sativa (arroz) y Aspergillus; su desarrollo obedeció a la necesidad de contar con herramientas para la búsqueda de genes que fueran útiles específicamente para el caso de genomas de pequeños eucariotes ya que en esta área los esfuerzos se han dirigido principalmente a los genomas bacterianos y al genoma humano.

Debido a que $P$. falciparum posee una densidad relativamente alta de genes (aproximadamente, $20 \%$ ) con respecto al ADN humano (aproximadamente, $1 \%-3 \%)$, el uso de programas desarrollados para el genoma humano y otros organismos con bajas densidades génicas (como muchos vertebrados y plantas superiores) puede no ser óptimo para la predicción de genes en $P$. falciparum u otros pequeños eucariotes ya que se pueden perder muchos posibles genes. Por otra parte, los programas desarrollados para 
procariotes no resultan útiles debido a su incapacidad para hallar intrones (38). Muchos de los 210 genes del cromosoma 2 de $P$. falciparum se encontraron usando GLIMMERM y algunas de estas predicciones se confirmaron mediante experimentos de laboratorio adicionales usando RT-PCR (40).

Al realizar el anillaje de los iniciadores utilizados previamente para los ensayos de PCR y RT-PCR sobre la secuencia completa del posible gen de TERT de $P$. falciparum, se comprobó que los tamaños esperados para las regiones codificantes de los dominios T y BCD están de acuerdo con los obtenidos experimentalmente. En el caso del producto que se esperaría con los iniciadores Ts y BCDas1 o Ts y BCDas2, existe discrepancia con los resultados experimentales. Se esperaría obtener un producto mayor de 3.000 pb (3 kb) mientras que experimentalmente se obtuvo un fragmento de $1.800 \mathrm{pb}$, aproximadamente, tanto en los ensayos de PCR como en los de RT-PCR. Este hallazgo resulta contradictorio, teniendo en cuenta que mediante experimentos adicionales (PCR anidado e hibridación (dot-blot), mostrados en la figura 2) se comprobó que el fragmento de 1.800 pb contiene los de 600 pb (región codificante para el dominio T) y 200 pb (región codificante para parte del dominio BCD). Esta situación podría deberse tanto a la generación de artefactos en la reacción de PCR con los iniciadores Ts-BCDas1 y Ts-BCDas2 como a la probabilidad de error que existe cuando se emplean métodos computacionales de comparación y búsqueda. Este hecho pone de manifiesto que los resultados encontrados mediante el uso de herramientas bioinformáticas deben ser sometidos a la comprobación experimental.

La posible presencia de artefactos de amplificación en las reacciones con los iniciadores Ts-BCDas1 y Ts-BCDas2 explicaría en parte la baja eficiencia de amplificación con los iniciadores Ts-BCDas1 y podría ser una explicación para los resultados anómalos obtenidos en la reacción de PCR anidado (discrepancia de tamaño del producto obtenido con los iniciadores Ts y Tas sobre el fragmento de 1800 pb y sobre ADN genómico del parásito, figura 3, carriles 1 y 2). La generación de artefactos 0 amplificaciones anómalas es un fenómeno que ha sido descrito en la literatura y que resulta crítico sobre todo en aplicaciones como la genotipificación $(41,42)$. En este caso, si bien es cierto que la longitud del producto obtenido no corresponde a la esperada teóricamente, los resultados experimentales permiten establecer que dicho fragmento sí corresponde a parte del gen de TERT de $P$. falciparum.

La secuencia identificada con el programa GLIMMERM se incluyó en un nuevo alineamiento; allí se identificó nuevamente la presencia del motivo $\mathrm{T}$, propio de la familia de las telomerasas que para la secuencia de $P$. falciparum está ubicado entre los aa 1043 y 1095. El motivo T y otros posibles motivos descritos como CP y CP2 parecen estar involucrados en la unión ARN -TERT $(43,44)$. Teniendo en cuenta la conservación, al menos, del motivo T en todas las TERT, su función de unión al ARN podría ser presumiblemente compartida en todas las especies (45).

Además del motivo $\mathrm{T}$, se identificaron sobre la secuencia de $P$. falciparum los 7 dominios descritos de transcriptasas reversas (motivos 1 , 2, A, B, C, D y E) que están presentes en las TERT. Dentro de los motivos de transcriptasa reversa, existe una tríada de ácidos aspárticos localizados en los motivos $A$ y $C$ que son indispensables para la actividad pues coordinan los cationes divalentes $\left(\mathrm{Mg}^{++}\right)$que se requieren para la catálisis $(19,46-48)$. Mutaciones en cualquiera de estos tres ácidos aspárticos de las TERT de levaduras, humano o Tetrahymena, eliminan la actividad de la telomerasa tanto in vitro como in vivo $(16,21,29,48-50)$. En la secuencia de $P$. falciparum estos residuos están presentes en las posiciones 1595: motivo A y 1982, 1983: motivo C. Los motivos RT presentes en las TERT, incluida la posible TERT de $P$. falciparum, presumiblemente contribuyen a un plegamiento terciario común similar al modelo de "mano derecha" que se observa en las estructuras cristalinas de otras transcriptasas reversas como la del virus de inmunodeficiencia humana (HIV-1 RT). En este modelo es posible distinguir los dominios estructurales de dedos (fingers), palma (palm) y pulgar (thumb) con el sitio activo ubicado en el dominio de palma. 
Una característica prominente de la región de unión del nucleótido en las RT es la presencia de una tirosina $(Y)$ o fenilalanina $(F)$ cinco residuos después del ácido aspártico conservado del motivo $A$; en efecto, la secuencia de $P$. falciparum contiene una tirosina $(Y)$ en este residuo. En esta posición, un aminoácido con una cadena lateral grande discrimina rNTP de dNTP; esto ha sido demostrado experimentalmente para el caso de la telomerasa de Tetrahymena (51). El motivo A en las TERT parece estar posicionado en una forma similar a otras RT con relación al azúcar del nucleósido trifosfato que ingresa. Considerando adicionalmente la tríada de ácido aspártico en los motivos A y C, podría decirse que residuos claves en el dominio de palma completo parecen estar posicionados de manera similar en TERT y RT convencionales (51).

Estudios estructurales de la RT del HIV-1 implican a una lisina $(\mathrm{K})$ conservada en el motivo 1 y una arginina $(R)$ en el motivo 2 como responsables del contacto con los grupos fosfato $\mathrm{g}$ y a, respectivamente, del nucleótido que ingresa; estos residuos se encuentran conservados en las TERT alineadas, incluso la de $P$. falciparum. Existen evidencias experimentales que confirman el papel de estos residuos en la telomerasa de Tetrahymena lo que sugiere que estos residuos en los motivos 1 y 2 , adicionales a los de $A$ y $C$ antes mencionados, juegan papeles similares en TERT y otras RT (51).

Los residuos de TERT equivalentes a los presentes en RT soportan una conservación del mecanismo catalítico básico entre estas dos clases de enzimas: la tríada de ácido aspártico de los residuos $A$ y $C$ es indispensable para la actividad en ambos tipos de enzimas $(16,21,29,48-50)$. La misma tirosina $(\mathrm{Y})$ conservada en el motivo $\mathrm{A}$ permite tanto a las TERT como a las RT discriminar la incorporación de nucleótidos (51). Aunque algunos otros residuos cruciales en las RT, como la glutamina $(Q)$ en el motivo $B$, parecen ser menos importantes en la telomerasa (48); se ha sugerido que, a pesar del alto grado de divergencia en secuencia entre las TERT y las RT convencionales, los mecanismos de polimerización pueden ser muy similares.
Un estudio con TERT de levadura que involucra comparaciones de secuencia, mutagénesis y ensayos bioquímicos, describe nuevos motivos conservados hacia la región $\mathrm{N}$ terminal de TERT, diferentes de los motivos RT. Estos son llamados GQ, CP y QFP (30) y corresponden a los descritos por otros autores como I, II y III (52). En las secuencias alineadas, la conservación de residuos no es muy evidente en esta región. Aquí debe tenerse en cuenta que éste es un alineamiento global que buscaba revelar la presencia de motivos comunes a todas las TERT. Para indagar sobre motivos particulares para un grupo de especies (por ejemplo, ciliados, levaduras, vertebrados, etc.) o para una región en particular (por ejemplo, región $\mathrm{N}$-terminal, C-terminal, etc.) deben llevarse a cabo nuevos alineamientos locales donde la longitud de las secuencias alineadas se restrinja y se utilicen matrices apropiadas para alineamientos locales más que globales.

Al realizar la comparación global de las secuencias de TERT, incluida la de $P$. falciparum (figura 5) puede notarse que la de $P$. falciparum posee espaciadores más largos entre los motivos, particularmente entre los motivos de transcriptasa reversa y el motivo $\mathrm{T}$ (aproximadamente, $300 \mathrm{aa}$ ). Este hecho podría tener implicaciones estructurales en cuanto al plegamiento de la proteína lo cual podría estar relacionado con el elemento ARN de la telomerasa el cual es desconocido en el caso de $P$. falciparum.

Aunque con el abordaje realizado no es posible definir con exactitud los límites del gen de TERT, la identificación de los elementos de secuencia evolutivamente conservados junto con la comprobación de la presencia y transcripción del gen en el parásito, constituyen un punto de partida importante para el estudio de TERT y, por ende, de la telomerasa en $P$. falciparum. Los hallazgos aquí reportados permitirán llevar a cabo otros acercamientos experimentales entre los que pueden contarse la producción de una proteína recombinante y la obtención de anticuerpos que permitan detectar y aislar el complejo telomerasa completo. Por otra parte, la estandarización de las reacciones de RT-PCR y los iniciadores diseñados pueden ser utilizados para hacer un 
seguimiento indirecto de la expresión de la proteína a lo largo del ciclo de vida del parásito. Así mismo, el abordaje aquí mostrado puede resultar útil para estudiar problemas similares en otros organismos o con otras proteínas.

\section{Conflicto de intereses}

Los autores declaramos que no existen conflictos de intereses que puedan influir de manera alguna en los resultados presentados en este trabajo.

\section{Financiación}

Este trabajo fue financiado por el Instituto Nacional de Salud, la Universidad Nacional de Colombia (proyecto DINAIN 2010100198) y el Instituto Colombiano para el Desarrollo de la Ciencia y la Tecnología "Francisco José de Caldas" (Colciencias) (proyecto 11010511422).

\section{Referencias}

1. Price C. Telomeres: capping off the ends. Nature 1999; 397:213-4.

2. Liu J. Studies of the molecular mechanisms in the regulation of telomerase activity. FASEB J 1999;13:2091104.

3. Prescott J, Blackburn E. Telomerase: Dr. Jekyll or Mr. Hyde? Curr Opin Gen Dev 1999;9:368-73.

4. Greider C, Blackburn E. Identification of a specific telomere terminal transferase activity in Tetrahymena extracts. Cell 1985;43:405-13.

5. Greider C, Blackburn E. The telomere terminal transferase of Tetrahymena is a ribonucleoproteine enzime with two kinds of primer specificity. Cell 1987; 51:887-98.

6. Le S, Sternglanz R, Greider C. Identificaction of two ARN-binding proteins associated with human telomerase RNA. Mol Cell Biol 2000;11:999-1010.

7. Blackburn E. The telomere and the telomerase: How do they interact? Mount Sinai J Med 1999;66:292-300.

8. Collins K. Ciliate telomerase biochemistry. Ann Rev Biochem 1999;68:187-218.

9. Aldous W, Martin R, Kyle D. Stage specific detection and inhibition studies of Plasmodium falciparum telomerase. Mol Biochem Parasitol 1998;95:281-5.

10. Bottius E, Bakhsis N, Sherf A. Plasmodium falciparum telomerase: de novo telomere addition to telomeric and nontelomeric sequences and role in chromosome healing. Mol Cell Biol 1998;18:919-25.

11. Sriwilaijareon N, Petmitr S, Mutirangura $A$, Ponglikitmongkol M, Wilairat P. Stage specificity of
Plasmodium falciparum telomerase and its inhibition by berberine. Parasitol Int 2002;51:99-103.

12. Nugent $\mathbf{C}$, Lundblad V. The telomerase reverse transcriptase: components and regulation. Genes Dev 1998;12:1073-85

13. Lingner J, Cech T. Purification of telomerase from Euplotes aediculatus: requirement of a primer $3^{\prime}$ overhang. Proc Nat Acad Sci USA 1996;93:10712-7.

14. Lendvay T, Morris D, Sah J, Balasubramian B, Lundblad V. Senescence mutants of Saccharomyces cerevisiae with a defect in telomere replication identify three additional EST genes. Genetics 1996;144:1399412.

15. Lingner J, Cech T, Hughes T, Lundblad V. Three ever shorter telomere (EST) genes are dispensable for in vitro yeast telomerase activity. Proc Nat Acad Sci USA 1997;94:11190-5.

16. Harrington L, McPhail T, Mar V, Zhou W, Oulton R, Program $\mathrm{E}$ et al. A mammalian telomerase-associated protein. Science 1997;275:973-7.

17. Kilian A, Bowtell D, Abud H, Hime G, Venter D, Keese $P$ et al. Isolation of a candidate human telomerase catalytic subunit gene, which reveals complex splicing patterns in different cell types. Hum Mol Genet 1997;6:2011-9.

18. Meyerson M, Counter M, Eaton E, Ellisen W, Steiner $\mathrm{P}$, Caddle $\mathrm{S}$ et al. hEST2, the putative human telomerase catalytic subunit gene, is upregulated in tumor cells and during immortalization. Cell 1997;90:785-95.

19. Nakamura T, Morin G, Chapman K, Weinrich S, Andrews $\mathbf{W}$, Lingner $\mathbf{J}$ et al. Telomerase catalytic subunit homologs from fission yeast and human. Science 1997;277:955-9.

20. Bryan T, Sperger J, Chapman K, Cech T. Telomerase reverse transcriptase genes identified in Tetrahymena thermophila and Oxytricha trifallax. Proc Nat Acad Sci USA 1998;95:8479-84.

21. Collins K, Gandhi L. The reverse transcriptase component of the Tetrahymena telomerase ribonucleoprotein complex. Proc Nat Acad Sci USA 1998; 95:8485-90.

22. Greenberg R, Allsopp R, Chin L, Morin G, DePinho R. Expression of mouse telomerase reverse transcriptase during development, differentiation and proliferation. Oncogene 1998;16:1723-30.

23. Fitzgerald M, Riha K, Gao F, Ren S, McKnigth K, Shippen D. Disruption of the catalytic telomerase subunit gene from Arabidopsis inactivates telomerase and leads to a slow loss of telomeric DNA. Proc Nat Acad Sci USA 1999;96:14813-8.

24. Oguchi K, Liu H, Tamura K, Takahashi H. Molecular cloning and characterization of AtTERT, a telomerase 
reverse transcriptase homolog in Arabidopsis thaliana. FEBS Lett 1999;457:465-9.

25. Metz A, Love R, Strobel G, Long D. Two telomerase reverse transcriptases (TERTs) expressed in Candida albicans. Biotechnol Appl Biochem 2001;34:47-54.

26. Malik H, Burke W, Eickbush T. Putative telomerase catalytic subunits from Giardia lamblia and Caenorhabditis elegans. Gene 2000;251:101-8.

27. Kuramoto $\mathbf{M}$, Ohsumi $\mathrm{K}$, Kishimoto $\mathrm{T}$, Ishikawa $\mathbf{F}$. Identification and analyses of the Xenopus TERT gene that encodes the catalytic subunit of telomerase. Gene 2001;277:101-10.

28. Nakamura T, Cech T. Reversing time: origin of telomerase. Cell 1998;92:587-90.

29. Weinrich S, Pruzan R, Ma L, Ouellette M, Tesmer V, Holt $S$ et al. Reconstitution of human telomerase with the template ARN component hTR and the catalytic protein subunit hTRT. Nat Genet 1997;17:498-502.

30. Xia J, Peng Y, Mian S, Lue N. Identificaction of functionally important domains in the $\mathrm{N}$-terminal region of telomerase reverse transcriptase. Mol Cell Biol 2000;20: 5196-207.

31. Trager W, Jensen J. Human malaria parasites in continuous culture. Science 1976;193:673-5.

32. Attwood T, Parry-Smith J. Introduction to bioinformatics. First edition. London: Addison Wesley Longman; 1999. p.35-66, 132-42.

33. The Plasmodium Genome Resource [online]. [2000?] [2000-1]; disponible en: URL: http:// www. plasmodb.org.

34. GlimmerM Web Interface [software online]. [1999] [2001-2]; disponible en: URL: http://www.tigr.org/tdb/ glimmerm/glmr_form.html.

35. Gasteiger E, Gattiker A, Hoogland C, Ivanyi I, Appel RD, Bairoch A. ExPASy: the proteomics server for indepth protein knowledge and analysis [online]. [1993] [2000-2]; disponible en URL: http://www.expasy.org

36. Edy S. Multiple-alignment and sequence searches. Trends guide to bioinformatics. Immunology Today 1998; 19(Suppl.):15-7.

37. Brenner S. Practical database searching. Trends guide to bioinformatics. Immunology Today 1998;19(Suppl.): 9-12.

38. Salzberg S, Pertea M, Delcher A, Gardner M, Tettelin H. Interpolated Markov models for eukaryotic gene finding. Genomics 1999;59:24-31.

39. Delcher A, Harmon D, Kasif S, White O, Salzberg S. Improved microbial gene identification with GLIMMER. Nucleic Acids Res 1999;27:4636-41.
40. Gardner M, Tettelin H, Carucci D, Cummings L, Aravind L, Koonin E et al. Chromosome 2 sequence of the human parasite Plasmodium falciparum. Science 1998;282:1126-32.

41. Imwong M, Pukrittakayamee S, Looareesuwan $\mathbf{S}$, Poirriez J, Pasvol G, White $\mathbf{N}$ et al. Plasmodium vivax: polimerase chain reaction artifacts limit the suitability of pvgam1 as a genetic marker. Exp Parasitol 2001;99:175-9.

42. Qiu $X, W u L$, Huang $H$, McDonel P, Palumbo A, Tiedje $\mathrm{J}$ et al. Evaluation of PCR-generated chimeras, mutations and heteroduplex with 16S rRNA gene-based cloning. Applied Environm Microbiol 2001;67:880-7.

43. Lai C, Mitchell J, Collins K. ARN binding domain of telomerase reverse transcriptase. Mol Cell Biol 2000;21: 990-1000.

44. Bryan T, Goodrich K, Cech T. Telomerase RNA bound by protein motifs specific to telomerase reverse transcriptase. Mol Cell 2000;6:493-9.

45. Bosoy D, Lue N. Functional analysis of conserved residues in the putative "finger" domain of telomerase reverse transcriptase. J Biol Chem 2001;276:4630512.

46. Jacobo-Molina A, Arnold E. HIV reverse transcriptase structure-function relationships. Biochemistry 1991;30: 6351-6.

47. Joyce $C$, Steitz T. Function and structure relationships in DNA polymerases. Annu Rev Biochem 1994;63:777822.

48. Lingner J, Hughes T, Shevchenko A, Mann M, Lundblad V, Cech T. Reverse transcriptase motifs in the catalytic subunit of telomerase. Science 1997;276: 561-7.

49. Beatie T, Zhou W, Robinson M, Harrington L. Reconstitution of human telomerase activity in vitro. Curr Biol 1998;8:177-80.

50. Haering C, Nakamura T, Baumann P, Cech T. Analysis of telomerase catalytic subunit mutants in vivo and in vitro in Schizosaccharomyces pombe. Proc Nat Acad Sci USA 2000;97:6367-72.

51. Miller M, Collins K. The Tetrahymena p80/p95 complex is required for proper telomere length maintenance and micronuclear genome stability. Mol Cell 2000;6:827-37.

52. Friedman K, Cech T. Essential functions of aminoterminal domains in the yeast telomerase catalytic subunit revealed by selection for viable mutants. Genes Dev 1999;13:2863-74. 